2. Litovchenko, Yu. K. (2003). Teploprovodnost poristyih tel. Metallurgicheskaya teplotehnika. Sbornik nauchnyih trudov Natsionalnoy metallurgicheskoy akademii Ukrainyi, vol. 9. Dnepropetrovsk: NMetAU, 197.

3. Yurev, Yu. L. (2014). Sovershenstvovanie proizvodstva uglerodnyih materialov na osnove beryozovoy drevesinyi: phD thesis. Ekaterinburg: Uralskiy gosudarstvennyiy lesotehnicheskiy universitet, 256.

4. Myronov, A., Ved V. (2015). Determination of rational parameters for energy efficient drying process of different wood species. Computer Aided Process Engineering (CAPE). Paderborn, Germany: CAPE Forum 2015, 67-69.

5. Tayts, N. Yu. (1962). Tehnologiya nagreva stali. M.: Metallurgizdat, 567.

Отримано в редакцію 22.04.2018

Прийнято до друку 30.06.2018
Received 22.04.2018

Approved 30.06.2018

\title{
ВОЗДЕЙСТВИЕ ГИДРОДИНАМИЧЕСКОЙ КАВИТАЦИИ НА БИОЛОГИЧЕСКИЕ КЛЕТКИ. МЕХАНИЗМЫ, ТЕХНОЛОГИИ, ПРИМЕНЕНИЕ
}

\author{
Гоженко Л.П., к.т.н., Недбайло А.Е., к.т.н., Иваницкий Г.К., д.т.н. \\ Институт технической теплофизики НАН Украины, г. Киев
}

\begin{abstract}
Аннотация. Целью данной работы является раскрыть механизмы воздействия кавитации на биологические клетки для создания новых технологий и оборудования, а также усовершенствования уже существующих. Анализ современной литературы показал, что процесс кавитаџии широко используется в пищевой, химической, фармацевтической, биологической промышленности и является эффективным с экологической, энергетической точки зрения. При этом, сточт отметить, что использования кавитации в технологиях существенно сокращует время ведения процесса обработки, а также минимизирует температурное воздействие, по сравнению с традиционными технологиями, что особенно актуально при работе с биологически-активными веществами. Кавитаџионные процессы используются в технологиях экстракции растительного сырья, стерилизаџии жидкостных сред как в пищевой промышленности, так и в технологиях водоподготовки и водоочистки. Не смотря, на то, что кавитацию широко применяют на практике, литературный анализ показал, что механизмы воздействия на клетки изучень не в полной мере. В статье предложены механизмы и их теоретическое обоснование для процесса экстракции и стерилизации, определены теплофизические параметры необходимые для ведения того или иного процесса. В зависимости от сферы применения кавитации ее интенсивность и механизм воздействия должны определяться свойствами целевого продукта. Соответственно, для отдельных иелей параметры ведения процесса должны обеспечить полное разрушение клетки, а для других необходимо и достаточно повысить проницаемость мембраны клетки для выхода целевого компонента. В связи с этим, существует необходимость тонкого подбора теплофизических параметров процесса, а также технологического оборудования, соответственно.
\end{abstract}

Ключевые слова: кавитация, экстракция, стерилизация, биологические клетки

\section{THE INFLUENCE OF HYDRODYNAMICAL CAVITATION ON BYOLOGICAL CELLS. MECHANISMS, TECHNIQUES, APPLICATION}

\author{
Gozhenko L. P., PhD, Nedbailo A. Y., PhD, Ivanytskiy G. K., DSc. \\ Institute of Engineering Thermophysics of NAS of Ukraine., Kyiv
}

\begin{abstract}
The purpose of this work is to found the mechanisms of the effect of cavitation on biological cells for the creation of new technologies and equipment, as well as the improvement of existing ones. Analysis of present literature has shown that the process of cavitation is widely used in the food, chemical, pharmaceutical, and biological industries and is effective from an ecological, energy point of view. At the same time, it should be noted that the use of cavitation in technologies significantly reduces the processing time, as well as minimizes the temperature effect, in comparison with traditional technologies, which is especially important for biologically active substances. Cavitation processes are used in technologies of extraction of plant raw materials, sterilization of liquid media both in the food industry, and in technologies of water treatment and water purification. Despite the fact that cavitation is widely used in practice, literary analysis has shown that mechanisms of action on cells have not been fully studied. Novel studies presents mechanisms, which ascertain fact of cell wall full or partially distruction, but not explain reasons of this. There is not explaining of the decrease in internal massexchange resistances. The article proposes mechanisms and their theoretical justification for the extraction and sterilization process, and the thermophysical parameters necessary for conducting a particular process are determined.
\end{abstract}


Cavitation intensity and mechanism of action should be determined by the properties of the target product and should be depend on the scope of application. So, for some purposes, the process parameters must ensure complete destruction of the cell, while for others it is necessary and sufficient to increase the permeability of the cell membrane to yield the target component. In this regard, there is a need for a thin adjustment of thermophysical process parameters, as well as technological equipment, respectively.

Key words: cavitation, extraction, sterilization, biological cells.

Введение. В последнее время появилось много научных работ по применению кавитации в технологиях экстракции и стерилизации [1 - 4]. Хорошо описаны процесс кавитации, ее теплофизические и гидродинамические параметры $[1,2]$. Авторы отмечают, что сильнейшие гидродинамические эффекты наблюдаются во время схлопывания кластера кавитационных пузырьков, что сопровождается образованием микротурбулентных течений, кумулятивных струек, сильных сдвиговый напряжений. Помимо гидродинамического воздействия в области кавитационного кластера создаются условия высоких температур и давлений (закритическая область). При этом нужно отметить, что такое состояние сохраняется короткое время - несколько наносекунд, что достаточно для протекания химических реакций, но недостаточно для денатурации термолабильных компонентов системы. В кавитационной полости при ее схлопывании температура и давление достигают наивысшего пика -10000 К и 1000 атм соответственно.

Анализ проблемы и литературных источников. Постановка задачи исследований. Исследователи кавитационного воздействия на биологические клетки описывают высокую эффективность обработки при применении данного процесса, при этом отмечается снижение времени процесса обработки, сокращение энергозатрат, уменьшение количества химических реагентов при стерилизации или растворителя при экстракции, экологичность технологий. Многие отмечают комплекс воздействий, способствующих интенсификации экстракции при кавитации: фрагментация, эрозия, ультразвуковой капиллярный эффект, сонопорирование (Sonoporation), действие локальных сдвиговых напряжений [3].

Однозначно можно сказать, что воздействие кавитации на клетки приводит к их полному или частичному разрушению, что подтверждается микроскопическими исследованиями образцов растительного сырья и бактериальных клеток после кавитационной обработки. Однако, универсального механизма разрушения структуры клетки, влияния теплофизических параметров процесса, их течения на границе клеточная мембрана - окружающая среда, а также цитоплазма - мембрана клетки не изучены. По нашему мнению, механизмы связанные с повреждением клетки при воздействии кумулятивных струй маловероятны и могут влиять лишь на ту малую часть сырья, которая находится у твердых поверхностей.

В данной работе перечислен ряд механизмов воздействия кавитации на растительные клетки при экстракции, связаных с полным разрушением клетки, вскипанием жидкости внутри клетки, воздействием знакопеременного давления на клетку, а также ростом газовых пузырьков внутри клетки при снижении давления.

При экстракции из растительного сырья стадия внутреннего диффузионного переноса заключается в проникновении растворителя (экстрагента) к внутренним клеточным структурам. При этом возможен либо непосредственный контакт экстрагента с содержанием разрушенных клеток, или диффузия экстрагента через пористую оболочку клетки, которая замедляет скорость процесса экстрагирования. Для каждого вида растительного сырья величина сопротивления клеточной оболочки массопереноса зависит от физико-химической природы и структуры экстрагированного материала. Внутренняя диффузия тяжело поддается внешнему влиянию, но, как показали многочисленные экспериментальные исследования и практический опыт, ее скорость можно существенно увеличить путем применения знакопеременного давления при акустическом и гидродинамическом воздействии на сырье с инициированием кавитационных эффектов.

При экстрагировании из растительного сырья интенсивность процесса определяется разницей концентраций целевого компонента в клетке и экстрагенте и суммой внутренних и внешних сопротивлений.

Внешние сопротивления, обусловленные условиями конвекции в экстрагенте вокруг частиц сырья. Внутренние сопротивления, которые на порядки превышают внешние, состоят из сопротивлений клеточной стенки и межклеточного пространства. Традиционные методы интенсификации экстракции связанные с уменьшением только внешних сопротивлений. Однако это не позволяет полностью исключить целевое вещество. В последние годы применяются перспективные методы, направленные на интенсификацию внутренних процессов. Это прежде всего кавитация, или создание знакопеременного давления в среде.

Процесс кавитации обусловлен падением давления среды до отрицательных значений и его мгновенным повышением, что обуславливает зарождение парогазовых пузырьков и их последующие схлопывание. Такое явление может происходить и внутри клетки. На этапе роста газового пузырька жидкость с целевым компонентом будет вытесняться через клеточную мембрану за счет заполнения клеточного пространства парогазовым пузырьком. В условиях знакопеременного давления данный процесс происходит многократно, что обуславливает максимальный выход целевого вещества. 
Полное разрушение клеточной стенки растения нежелательно, т.к. помимо целевого компонента, в экстракт выделятся балластные вещества. Поэтому для получения качественных экстрактов необходим подбор оптимальных параметров процесса кавитации в зависимости от конкретного сырья.

На ряду с воздействием кавитации на растительные клетки практический интерес представляет возможность разрушения бактериальных клеток и используется при лизисе клеток для экстракции внутриклеточных компонентов, пастеризации пищевых сред, в процессах водоочистки. Содержимое бактериальной клетки - цитоплазма, которая представляет коллоидный раствор аминокислот, ферментов, углеводов, солей и др., отделена от окружающей жидкости тонкой (8..10 нм) полупроницаемой плазматической мембраной с диаметром пор (ионных каналов) 0,4...0,5 нм. Внутренняя поверхность мембраны подвергается действию осмотического давления цитоплазмы (0,3 . . 1,0 МПа). Растягиванию и разрыву мембраны под действием осмотического давления препятствует окружающий ее прочный каркас - тонкая клеточная стенка с крупными порами (4...5 нм), проницаемая для воды, солей и низкомолекулярных соединений. Предел прочности клеточных стенок микроорганизмов достигает 100 МПа, что сравнимо с пределом прочности некоторых сортов стали [4]. Роль механизмов кавитации в инактивации бактериальных клеток далеко не изучена. Гибель микроорганизмов связывается с гидромеханическими, термическими, химическими, электрическими эффектами кавитации или с совокупным действием этих факторов.

Большинство исследователей склоняются к мнению, что роль кавитации в разрушении бактериальных клеток заключается в действии ударного и сдвигового механизмов на завершающей стадии сжатия кавитационного кластера $[1,3]$. Однако детализация этих механизмов на микроуровне и количественный расчет силового действия кавитации на клетки не проводились.

При проведении анализа влияния ударных импульсов давления, излучаемых кавитационным кластером, считалось, что бактериальная клетка в форме сферы или цилиндрической палочки находится в равновесии с жидкой средой с давлением $p_{l 0}=0,1$ МПа. На внутреннею поверхность клеточной стенки с толщиной $h_{c}$ через прилегающий к ней эластичную полупроницаемую мембрану действует осмотическое давление $\pi>>P_{l 0}$, вследствие чего в стенки возникают растягивающие напряжения $\sigma$. Величины тангенциального $\sigma_{t}$ и нормального напряжения в клеточной стенки бактерии-палочки оценивается по формулам:

$$
\sigma_{t}=p_{c} R_{c} / h \text { и } \sigma_{n}=p_{c} R_{c} / 2 h,
$$

а нормальное напряжение в стенке бактерии в форме сферы - по формуле:

$$
\sigma_{n}=p_{c} R_{c} / 2 h \text {. }
$$

$R_{c}$ - радиус цилиндрической части бактерии, а в (2) - радиус сферы. Параметр $p_{c}-$ давление, действующие на внутреннею поверхность стенки. При больших значениях $p_{c}$ величина растягивающего напряжения может превышать предел прочности стенки, что приводит к ее разрушению. Приведенные в таблице 1 характеристики размера $R_{c}$, толщины стенок $h_{c}$, величины граничных напряжений $\sigma$ для микроорганизмов взяты из литературных данных. В последнем столбике таблицы представлены рассчитанные по формулам (1) и (2) величины давлений $p=p_{c r}$, обеспечивающие превышения предела прочности и разрыв клеточной стенки.

Таблица 1

Оценка давления разрушения для микроорганизмов в зависимости от предела прочности стенки и размеров микроорганизмов

\begin{tabular}{|l|c|c|c|c|c|}
\hline Микроорганизм & Форма & $R_{c}$, мкм & $h_{c}$, нм & $\sigma_{c r}$, МПа & $p_{c r}$, МПа \\
\hline S. aureus & сферическая & 0,6 & 36 & 10 & 1,20 \\
\hline L.lactis & сферическая & 0,6 & 40 & 20 & 2,67 \\
\hline Lactobacillus & палочка & 0,4 & 35 & 20 & 1,75 \\
\hline E.coli & палочка & 0,3 & 12 & 3 & 0,80 \\
\hline
\end{tabular}

При резком повышении давления в окружающей жидкости $\left(p_{l}>p_{l 0}\right)$ внутреннее давление на клеточную стенку резко уменьшается, что приводит к ослаблению действующих в ней напряжений. При $p_{l}>\pi$ величина растягивающих напряжений в клетке $\sigma \rightarrow 0$. Приложенное к внешней поверхности плазматической мембраны избыточное давление $\Delta p=p_{l}-\pi$ приводит к сжатию цитоплазмы и возрастанию в ней внутреннего давления от $\pi$ до $p_{l}=\pi+\Delta p$. Как следствие, потенциальная энергия сжатой цитоплазмы возрастает, и после резкого сброса внешнего давления $p_{l}$ реализуется в форме ударного действия на внутреннею поверхность клеточной стенки и гибели клетки. 
Другим возможным механизмом динамического воздействия кавитации на бактериальные клетки является действие сдвиговых напряжений как результат суперпозиции радиальных течений, которые возникают в окрестности их роста и схлопывания. По литературным данным величины скорости сдвига, необходимые для разрушения грамположительных бактерий в форме сферы, лежат интервале $8 \cdot 10^{6} \ldots 9 \cdot 10^{7} \mathrm{c}^{-1}$, а для разрушения грамположительных бактерий в форме палочки достаточно скорости сдвига порядка $5 \cdot 10^{3} \ldots 7 \cdot 10^{5} \mathrm{c}^{-1}$.

Результаты исследований и их обсуждение.

Для подтверждения правомерности этих механизмов были проведены аналитические и экспериментальные исследования инактивации микрофлоры молока. В ИТТФ НАН Украины разработана технология термовакуумной обработки биологически активных жидких продуктов с целью повышения их качественных показателей. Эффективность термовакуумной технологии обусловлена инициированием в аппарате различных тепло- и гидродинамических эффектов, в том числе механизмов взрывного вскипания и кавитации. В данной технологии кавитационные эффекты реализуются в рабочем колесе центробежных насосов, которые в качестве продуктовых насосов используются для перекачивания жидкого продукта, и по условиям технологии номинально работают в кавитационном режиме. Молоко последовательно подвергается двукратному кавитационному воздействию. Первая стадия кавитационной обработки происходит в насосе, который работает в интервале температур $50 \ldots 60{ }^{\circ} \mathrm{C}$. После выхода из насоса молоко проходит термическую обработку в пастеризаторе $\left(T_{\max }=80 \ldots 95^{\circ} \mathrm{C}\right)$. Вторая стадия кавитационной обработки осуществляется перед выходом из аппарата в центробежном насосе, работающем в интервале температур $25 \ldots 30^{\circ} \mathrm{C}$. Уровень кавитационного воздействия в каждом из насосов, как показано ниже, зависит от температурного режима обработки.

После нагревания молока от $4{ }^{\circ} \mathrm{C}$ до $50 \ldots 60{ }^{\circ} \mathrm{C}$ и кавитационной обработки в первом насосе общая бактериальная обсемененность уменьшается более чем на два порядка (рис. 1). После термообработки в пастеризаторе при $T_{l}=95{ }^{\circ} \mathrm{C}$ этот показатель снижается еще более чем на порядок. После прохождения зоны адиабатного вскипания и последующей кавитационной обработки во втором насосе при $T_{l}=30^{\circ} \mathrm{C}$ обсемененность уменьшается почти на порядок. Количество бактерий S.aureus и E.coli снижается до нуля уже на первых этапах обработки, так как они характеризуются низкой прочностью стенки. В пробах, взятых на вы ходе из аппарата, практически отсутствуют выжившие клетки грамположительной палочки Lactobacillus, тогда как их содержание в пробах, взятых после пастеризатора еще довольно велико. После обработки в заметном количестве остаются лишь активные клетки L.lactis, обладающие более прочной клеточной стенкой. Выжившие бактерии этого класса определяют, в основном, уровень остаточной обсемененности молока.

Эксперимент показал, что подавление микрофлоры молока, наряду с влиянием эффектов кавитации, обусловлено также термическим воздействием на продукт в начальной стадии обработки и в пастеризаторе. Вместе с тем, заметный вклад в инактивацию микроорганизмов вносит кавитация, создаваемая в центробежных насосах. Большинство исследователей склоняются к мнению, что роль кавитации в разрушении бактериальных клеток заключается в действии ударного и сдвигового механизмов на завершающей стадии сжатия кавитационного кластера $[1,4,6]$.

На рис. 2 для разных значений температуры жидкости $T_{l}$ показаны рассчитанные в рамках модели [1] по данным работы [5] импульсы давления, излучаемые кавитационным кластером в рабочем колесе насоса в момент схлопывания пузырьков. При повышении температуры жидкости от 20 до $60{ }^{\circ} \mathrm{C}$ амплитуда импульсов $p_{l \max }$ понижается от 2,3 МПа до 1,2 МПа.

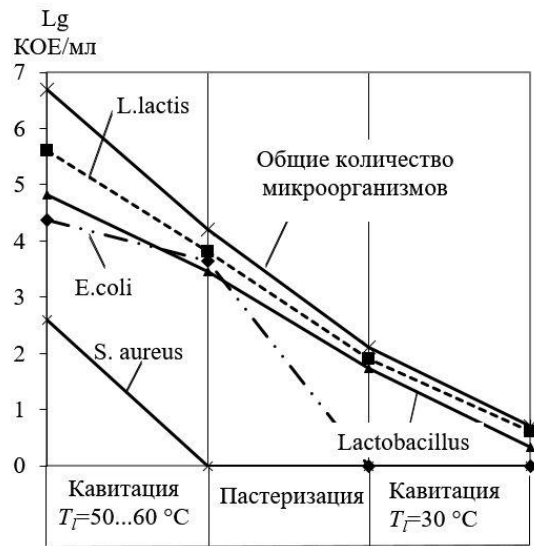

Рис. 1. Изменение общей бактериальной обсемененности и количества исследуемых бактериальных клеток на этапах термовакуумной технологии.

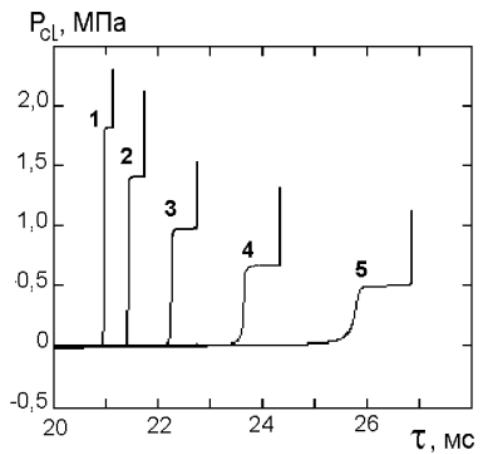

$1-20^{\circ} \mathrm{C} ; 2-30^{\circ} \mathrm{C} ; 3-40^{\circ} \mathrm{C} ; 4-50^{\circ} \mathrm{C} ; 5-$ $60^{\circ} \mathrm{C}$. Импульсы отвечают моменту схлопьвания пузырьков.

Рис. 2. Изменение во времени давления в объеме кавитационного кластера при разных значениях температуры жидкости $T_{1}$. 
Величина импульсов давления недостаточна для разрушения прочной клеточной стенки бактерий L.lactis, что согласуется с результатами эксперимента. Вместе с тем, полученные результаты показывают, что наблюдаемое в эксперименте интенсивное подавление жизнедеятельности бактерий Lactobacillus на завершающей стадии обработки при $T_{l}=30^{\circ} \mathrm{C}$, можно объяснить действием кавитации во втором насосе, когда реализуется условие $p_{l \max }=p_{c r}$.

На рис. 2 для разных значений температуры жидкости $T_{l}$ показаны рассчитанные в рамках модели [1] по данным работы [5] импульсы давления, излучаемые кавитационным кластером в рабочем колесе насоса в момент схлопывания пузырьков.

При повышении температуры жидкости от 20 до $60{ }^{\circ} \mathrm{C}$ амплитуда импульсов $p_{l \text { max }}$ понижается от 2,3 МПа до 1,2 МПа. Величина импульсов давления недостаточна для разрушения прочной клеточной стенки бактерий L.lactis, что согласуется с результатами эксперимента.

В работе [1] приведена система уравнений модели динамики ансамбля паровых пузырьков, позволяющая рассчитать мгновенные значения давления и вектора скорости в локальных точках внутри $3 \mathrm{D}$ кавитационного кластера на всех стадиях его эволюции. С помощью модели можно оценить уровень сдвиговых напряжений при различных условиях образования и развития кластера.

На рис. 3, а представлены расчетные данные по изменению величины скорости в плоскости XY, проходящей через центр кластера, в направлении $\mathrm{X}$ на участке длиной 0,3 мм для восьми последовательных значений координаты Y с интервалом 10 мкм. На рис. 3, б для того же момента времени показано изменение направления вектора скорости в тех же локальных точках.

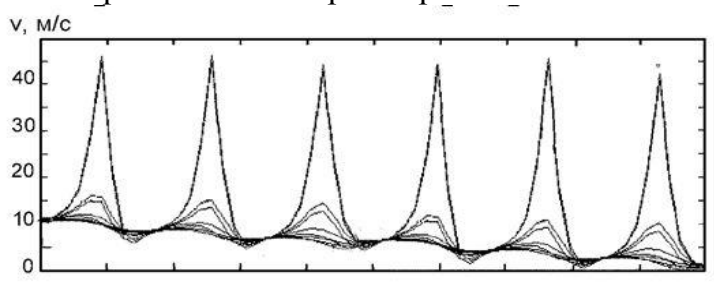

a)

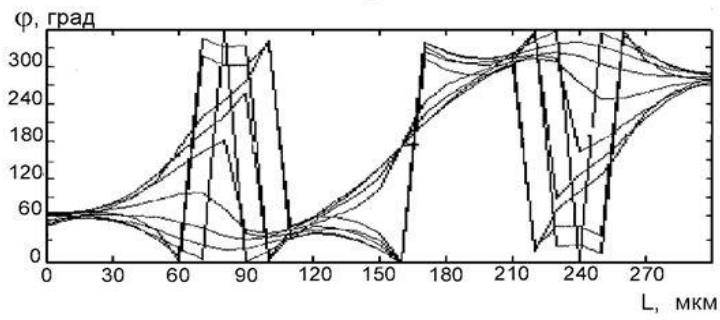

б)

Рис. 3. а) Изменение величины вектора скорости вдоль направления $X$ в 3D кавитационном кластере для восьми последовательных значений координаты Y с интервалом 10 мкм. б) Изменение направления вектора скорости в том же направлении $X$ для тех же значений координаты Y.

Для разрушения грамотрицательных палочек достаточны сдвиговые скорости порядка $5 \cdot 10^{3}$ $\ldots 7 \cdot 10^{5} \mathrm{c}^{-1}$.

Выводы. Использование кавитации при экстракции растительного сырья существенно интенсифицирует процесс за счет снижения не только внешних сопротивлений массопереноса, но и за счет снижения внутренней составляющей. Низкая температура ведения процесса позволяет обрабатывать термолабильное сырье. Существенный вклад кавитации в подавление нежелательной микрофлоры молока позволяет снижать температуру пастеризации. Уменьшение чрезмерного термического воздействия на термолабильный продукт способствует повышению его качественных показателей, а также энергоэффективности его переработки.

\section{Литература}

1. Тепломассообмен и гидродинамика в парожидкостных дисперсных средах / Долинский А.А., Иваницикий Г.К. Киев: Наукова думка, 2008. 381 с.

2. Jitendra Carpenter, Mandar Badve, Sunil Rajoriya, Suja George, Virendra Kumar Saharan and Aniruddha B. Pandit. Hydrodynamic cavitation: an emerging technology for the intensification of various chemical and physical processes in a chemical process industry // Reviews in Chemical Engineering. 2016. Vol. X. P. 3-37.

3. Farid Chemat, Natacha Rombaut, Anne-Gaëlle Sicaire, Alice Meullemiestre, Anne-Sylvie Fabiano-Tixier, Maryline Abert-Vian Ultrasound assisted extraction of food and natural products. Mechanisms, techniques, combinations, protocols and applications. A review. Ultrasonics Sonochemistry. 2017. Vol. 34. P. 540-560.

4. Chisti Yu., Moo-young M. Disruption of microbial cells for intracellular products. Reviewю Enzyme Microbiol. Techn. 1986. Vol. 8. P. $194-204$.

Наукові праці, Том 82, випуск 1 
5. Иваницкий Г.К., Недбайло А.Е. Аналитическое исследование кавитации в рабочем колесе центробежных насосов // Промышленная теплотехника. - 2012. - Т. 34, № 2. - C. $40-47$

6. Ashokkumar M, Rink R., Shestakov S. Hydrodynamic cavitation - an alternative to ultrasonic food processing. // Electronic Journal “Technical Acoustics” http://ejta.org, 2011. - № 9. - P. 1 - 10.

\title{
Reference
}

1. Dolinsky A.A., Ivanitsky G.K. Heat and mass transfer and hydrodynamics in vapor-liquid dispersed media. (2008), Kiev, Naukova dumka, 381

2. Jitendra Carpenter, Mandar Badve, Sunil Rajoriya, Suja George, Virendra Kumar Saharan and Aniruddha B. Pandit. (2016). Hydrodynamic cavitation: an emerging technology for the intensification of various chemical and physical processes in a chemical process industry. Reviews in Chemical Engineering. 10. 3 - 37.

3. Farid Chemat, Natacha Rombaut, Anne-Gaëlle Sicaire, Alice Meullemiestre, Anne-Sylvie Fabiano-Tixier, Maryline Abert-Vian.( 2017) Ultrasound assisted extraction of food and natural products. Mechanisms, techniques, combinations, protocols and applications. A review. Ultrasonics Sonochemistry. 34. 540 -560.

4. Chisti Yu., Moo-young M. (1986). Disruption of microbial cells for intracellular products. Review Enzyme Microbiol. Techn. 8. $194-204$.

5. Ivanitsky G.K., Nedbaylo A.E. Analytical study of cavitation in the impeller of centrifugal pumps. Industrial Heat Engineering, Kiev, (2011), 34(2), $40-47$.

6. Ashokkumar M., Krasulya O., Rink R. A New Look at Cavitation and the Applications of Its Liquid-Phase Effects in the Processing of Food and Fuel, Appl. Phys. Research, (2012), 4(1), 19 - 29.

Отримано в редакцію 27.04.2018

Прийнято до друку 01.07.2018
Received 27.04.2018

Approved 01.07.2018

DOI: http://dx.doi.org/10.15673/swonaft.v82i1.998

\section{ДОСЛІДЖЕННЯ СТІЙКОСТІ ТЕЧІЇ ГРАВІТАЦІЙНО СТІКАЮЧОЇ ПЛІВКИ РІДИНИ В ДВОФАЗНИХ СИСТЕМАХ}

\author{
Туз В.О. ${ }^{1}$, д.т.н., ЛебедьН.Л ${ }^{1}$,, к.т.н. \\ ${ }^{1}$ Національний технічний університет України \\ «Київський політехнічний інститут імені Ігоря Сікорського» \\ м. Київ, Україна
}

\begin{abstract}
Анотація. Використання методів пасивної інтенсифікацї̈ у вигляді поверхонь з капілярно-пористим покриттям в контактних апаратах істотно ускладнює гідродинамічну картину взаємодії системи «поверхня - плівка рідини - газовий потік». Інтенсифікуючи прочеси тепло- і масообміну, штучна шорсткість зменшує робочий діапазон контактних апаратів, шляхом зниження границі захлинання. Результати рішення математичної моделі системи «плівка рідини - газовий (паровий) потік» у вигляді системи диференціальних рівнянь з відповідними граничними умовами для гладкої вертикальної поверхні не коректно використовувати для визначення параметрів плівки при кризових явищах у випадку застосування каналів з капілярно-пористими структурами. Представлений аналіз результатів експериментального дослідження гідродинаміки двофазного потоку в каналах з капілярно-пористим покриттям, при відповідних граничних умовах, дозволив визначити верхній діапазон навантажень до початку захлинання по рідкій $і$ газовій фазах в контактних тепломасообмінних апаратах. Аналітичне рішення задачі з визначення гранищь кризових явищ з урахуванням результатів експериментального дослідження гідродинаміки двофазного потоку в каналах з капілярно-пористим покриттям, при відповідних граничних умовах, дозволило визначити верхній діапазон навантажень до початку захлинання по рідкій $і$ газовій фазах в контактних тепломасообмінних апаратах.
\end{abstract}

Ключові слова: гідродинаміка, плівка рідини, капілярно-пориста структура, границя захлинання

\section{STUDY OF FLOW STABILITY OF GRAVITATIONALLY FLOWING LIQUID FILM IN A TWO-PHASE SYSTEMS}

\author{
doctor of science V.O.Tuz ${ }^{1}$, candidate of technical sciences N.L.Lebed ${ }^{1}$ \\ ${ }^{1}$ National Technical University of Ukraine \\ "Igor Sikorsky Kiev Polytechnic Institute" \\ Ukraine, Kyiv
}

\begin{abstract}
The use of passive intensification methods in the form of surfaces with a capillary-porous coating in contact devices greatly complicates the hydrodynamic structure of the interaction of the system "surface liquid film - gas stream". Intensifying the processes of heat and mass transfer, artificial roughness increases the working range of contact devices, by reducing the break border.

The complexity of the analytical study of the stability of the system "liquid film - gas or steam flow" by solving a mathematical model, which is a system of differential equations with corresponding boundary conditions, consists in the fact that the functional dependence for the boundary phase separation is unknown. By using the
\end{abstract}

Наукові праці, Том 82, випуск 1
Scientific Works, Volume 82, Issue 1 